\title{
SIMULAÇÕES DE DESBASTES EM PLANTIOS DE Pinus caribaea Morelet var. caribaea Barrett \& Golfari
}

\author{
THINNINGS SIMULATION IN PLANTATIONS OF Pinus caribaea Morelet var. caribaea \\ Barrett \& Golfari
}

\author{
Ouorou Ganni Mariel Guera1 ${ }^{1}$, José Antônio Aleixo da Silva², Rinaldo Luiz Caraciolo Ferreira², \\ Daniel Álvarez Lazo ${ }^{4}$, Héctor Barrero Medel ${ }^{5}$ \\ 1,2,3 Programa de Pós-graduação em Ciências Florestais, Departamento de Ciência Florestal, Universidade \\ Federal Rural de Pernambuco, Recife, Pernambuco, Brasil-gueraforest@gmail.com, \\ jaaleixo@gmail.com \& rinaldo.ferreira@ufrpe.br \\ ${ }^{4,5}$ Departamento Forestal, Universidad de Pinar del Río "Hermanos Saíz Montes de Oca", Pinar del Río, \\ Cuba-daniel@upr.edu.cu\&hbarrero@upr.edu.cu
}

\begin{abstract}
RESUMO
Embora os desbastes, principalmente os seletivos, sejam partes das atividades silviculturais planejadas, os mesmos não são realizados sistematicamente na maioria das empresas florestais. Na maioria das áreas dessas empresas destinadas a produzir principalmente madeira serrada, são apenas definidos grandes espaçamentos iniciais prevendo a não realização de desbaste. Essa prática não favorece a obtenção de árvores de maiores dimensões com as características dentrométricas exigidas pelas serrarias. Por isso, a presente pesquisa teve como objetivo, simular desbastes para diferentes classes de sítio em plantios de Pinus caribaea Morelet var. caribaea Barr. \& Golf. estabelecidos para a produção de madeira para serraria na Empresa Florestal Integral (EFI) Macurije, Pinar del Río, Cuba. Com dados de parcelas permanentes, nas quais foram medidas as variáveis dendrométricas Diâmetro à altura do peito (DAP) e Altura total $(\mathrm{Ht})$, foi ajustado o sistema de prognose de produção de Buckman. Utilizando a equação de prognose de área basal, foram realizadas simulações mediante a aplicacão de diferentes intensidades de desbaste nas cinco classes de sitio predeterminadas na empresa. As vistas aéreas e em perspectivas das estruturas dos povoamentos remanescentes foram realizadas com o software SVS (Stand Visualization System). A alternativa ou intensidade de desbaste mais adequada sendo aquela que não é considerada severa, apresentando uma área basal remanescente superior a 19 m2.ha-1 (G > 19 m2.ha-1), os resultados das simulações indicaram que a intensidade de $20 \%$ foi a mais adequada para o sítio I, $15 \%$ para o sítio II e $10 \%$ para os sítios III, IV e V.
\end{abstract}

PALAVRAS-CHAVE: Desbaste seletivo, Índice de sítio, Madeira para serraria, Prognose de área basal.

\section{ABSTRACT}

Although thinnings, especially selective thinnings, are part of planned silvicultural activities, they are not systematically performed in most forest companies. In most areas of these companies destined to produce mainly sawn wood, only large initial spacings are defined, foreseeing the non-thinning. This practice does not favor the obtaining of larger trees with the dendrometric characteristics demanded by sawmills. Therefore, the present research had as objective, to determine the adequate thinning intensities for different classes of site in plantations of Pinus caribaea Morelet var. caribaea Barr. \& Golf. established for lumber production for the Integrated Forest Company (IFC) Macurije, Pinar del Río, Cuba. With data from permanent plots, in which the dendrometric variables Diameter at Breast Height (Dbh) and Total Height $(\mathrm{Ht})$, the Buckman production prognosis system was fitted. Using the basal area prognosis equation, simulations were performed by applying different thinning intensities to the five predetermined site classes in the company. The aerial and perspective views of the structures of the remaining stands were carried out with the SVS (Stand Visualization System) software. The most suitable alternative or intensity of thinning is one that is not considered severe, with a remaining basal area greater than $19 \mathrm{~m}^{2}$.ha-1 $\left(\mathrm{G}>19 \mathrm{~m}^{2}\right.$.ha-1), the simulation results indicated that the intensity of $20 \%$ was the most adequate for site $\mathrm{I}, 15 \%$ for site II and $10 \%$ for sites III, IV and V.

KEYWORDS: Selective thinning, Site index, Wood for sawmill, Prognosis of basal area. 


\section{INTRODUÇÃO}

Se inicialmente, as empresas florestais procuravam aumentar as extensões de seus plantios, na atualidade, os esforços estão focados em melhorar sua produtividade. As motivações principais dessa mudança são os altos custos de estabelecimento dessas grandes áreas que trazem consigo o crescimento exponencial dos custos de extração e transporte de madeira, atividades mais caras do processo produtivo florestal (SANTOS et al., 2016), que representam mais do $50 \%$ dos custos da madeira posta na indústria (MACHADO, 2014).

Um dos tratamentos silviculturais utilizados para melhorar essa produtividade é a aplicação de desbastes. Existem três métodos de desbaste: o método seletivo no qual árvores com defeitos e/ou dominadas são retiradas para facilitar o crescimento das dominantes; o método sistemático ou mecânico (Exemplo: desbaste em linha) aplicado geralmente em povoamentos uniformes no qual o critério de remoção das árvores é sua posição e é realizado para facilitar a aplicação de tratamentos silviculturais; e o método misto (seletivo-sistemático) que é uma combinação do dois, aplicando primeiro o desbaste seletivo e em seguida o mecânico (ASSMAN, 1970).

Existem numerosos métodos de determinação da melhor estratégia de desbaste. Entre outros se destacam: o método de determinação de intensidade de desbaste de Magin (1964) que consiste em determinar um fator $K$ que permite definir o volume de desbaste (K-Magin= Volume da árvore de área basal média do desbaste/ volume da árvore de área basal média do povoamento remanescente) e uma constante regulativa C; um modelo desenvolvido por Pienaar (1979) para prognose de crescimento e produção de povoamentos desbastados mediante um índice de supressão com base na área basal; Pienaar et al. (1985) modificam o mesmo índice possibilitando a determinação da idade de aplicação dos desbastes e focando principalmente no número de árvores removidas e remanescentes; o método de Burkhart et al. (1981) que possibilita avaliar diferentes intensidades e números de desbastes por meio de uma função de densidade de probabilidade como as funções Beta e de Weibull. A quase totalidade desses métodos passam pela modelagem matemática que, de acordo com Scolforo et al. (2001), tem que ser eficaz e produzir prognoses confiáveis para que qualquer uma das alternativas seja viável.

A aplicacão sistemática de desbastes é uma das tarefas mais difíceis da silvicultura. Embora os mesmos, principalmente os seletivos, sejam planejados e incluídos nas atividades silviculturais a serem realizadas, não são sistematizados e concretizados da forma planejada. Existem muitas áreas nas quais são apenas definidos grandes espaçamentos inicias prevendo a não realização de desbastes futuros devidos aos custos dos mesmos. $\mathrm{Na}$ Empresa Florestal Integral (EFI) Macurije, objeto deste estudo, os povoamentos não desbastados apresentam geralmente áreas basais com densidades entre 0,3 (30\%) e 0,4 (40\%) das áreas ocupadas (ALDANA et al., 2006). Segundo Campos \& Leite (2017), além da definição do espaçamento inicial, é preciso desbastar quando o objetivo do processo produtivo é produzir madeira para serraria.

Os baixos incrementos médios anuais reportados para o Pinus caribaea var. caribaea em pesquisas realizadas em áreas da EFI Macurije (BARRERO, 2010; BARRERO et al. 2011; GUERA, 2017) impedem a realização de desbaste severos que podem afetar a produção bruta. Na empresa, os desbastes são aplicados exclusivamente a povoamentos com densidade entre 0,8 e 1,0 (ALDANA et al., 2006). Os autores sustentam que é a máxima densidade na qual as árvores continuam seu crescimento sem significativa influência da competição.

Na empresa Macurije, como em Cuba, são aplicados três tipos de desbastes aos plantios de $P$. caribaea var. caribaea: o desbaste I cuja idade de aplicação é variável e pode ser determinada pelo critério de máximo incremento médio anual (IMA) em área basal (CAMPOS \& LEITE, 2017); o desbaste II entre os 16 e 25 anos para melhorar a forma do fuste e da copa; e o desbaste III aplicado geralmente depois dos 25 anos para a aceleração do crescimento e redução do tempo de obtenção de árvores com maiores DAPs (Diâmetros a Altura do Peito, medidos a altura de 1,30 m) (SUÁREZ et al., 2002).

A classificação da capacidade produtiva é a primeira etapa dos estudos de crescimento e produção em florestas plantadas. Mais conhecida como qualidade do local, pode ser definida como a produção esperada em um determinado local com um dado genótipo (espécie) e um regime de manejo específico (CLUTTER et al., 1983; SKOVSGAARD \& VANCLAY, 2008) ou como o potencial para produção de madeira em determinado lugar para determinada espécie ou clone (CAMPOS \& LEITE, 2017). A capacidade produtiva pode ser determinada por métodos diretos baseados no histórico de produtividade, no volume e na altura (Exemplo: índice de sítio) ou por métodos indiretos baseados no histórico de relações interespecíficas, nas características da vegetação e em fatores climáticos, edáficos e fisiográficos (CLUTTER et al., 1983).

O índice de sítio, técnica de classificação mais utilizada (ORTEGA \& MONTERO, 1988), é a altura dominante média 
do povoamento na idade índice (CAMPOS \& LEITE, 2017).

Embora diversas variáveis dentrométricas tenham sido utilizadas para a determinação de índice de sítio (altura média, diâmetro dominante e altura dominante), a mais utilizada por ser pouco influênciada pelos desbastes por baixo e pela densidade do povoamento, é a altura dominante definida por Assmann (1961) como a altura média das 100 árvores de maior diâmetro em um hectare. As curvas de índice de sítio anamórficas propostas para o P. caribaea por Barrero (2010) podem ser construídas por métodos da curva-guia e de Hammer e as polimórficas propostas por Guera (2017) para esta mesma espécie podem ser desenvolvidas por métodos da equação das diferenças e métodos da predição de parâmetros (CLUTTER et al., 1983).

Com base no exposto, o presente estudo foi realizado com o objetivo de determinar as intensidades de desbaste adequadas para diferentes classes de sítio em plantios de Pinus caribaea Morelet var. caribaea Barrett \& Golfari estabelecidos para a produção de madeira para serraria na Empresa Florestal Integral (EFI) Macurije, Pinar del Río, Cuba.

\section{MATERIAL E MÉTODOS}

Esta pesquisa foi realizada em povoamentos de $P$. caribaea var. caribaea da EFI Macurije, localizada entre as coordenadas $22^{\circ} 06^{\prime}$ a $22^{\circ} 42^{\prime}$ Latitude Norte e $83^{\circ} 48^{\prime}$ a $84^{\circ} 23^{\prime}$ Longitude Oeste, Pinar del Río, Cuba.

Para a representação das vistas aéreas e em perspectiva dos povoamentos antes e depois da aplicação das diferentes intensidades de desbaste, foi necessário medir para todas as árvores de uma parcela representativa selecionada: as coordenadas $X(m)$ e $Y(m)$, o DAP $(\mathrm{cm})$, a Altura $(m)$ e o Diâmetro da copa $(m)$.

Simulação de desbastes em plantios de $\boldsymbol{P}$. caribaea var. caribaea na empresa florestal Macurije

As simulações de desbaste por capacidade produtiva (classe de sítio) foram aplicadas baseando-se na equação de prognose de área basal resultante do sistema de prognose de Buckman modificado por Silva et al. (2006) e ajustado a dados provenientes de parcelas permanentes da EFI Macurije por Guera (2017) (Expressões 01 e 02). Este sistema presentou um melhor ajuste que os outros modelos testados (CLUTTER, 1963; SILVA \& BAILEY, 1986; CLUTTER \& JONES, 1980) para a prognose da produção de $P$. caribaea na EFI Macurije.

$$
\begin{gathered}
L n V_{2}=1,181-27,352 I_{2}^{-1}+0,004 S_{1}+1,291 L n G_{2} \\
\left(R_{a j}^{2}=98,97 \% ; R M S E=0,085 \%\right) \\
L n d G_{2}=-1,496+0,061 S_{1}-3,859 I_{2}^{-1}+1,045 G_{1} \\
\left(R_{a j}^{2}=61,650 \% ; R M S E=1,987 \%\right)
\end{gathered}
$$

Em que: $V_{2}=$ produção $\left(\mathrm{m}^{3}\right)$ esperada na idade $I_{2} ; I_{1}=$ idade atual; $I_{2}=$ idade futura; $G_{1}=$ área basal atual; $d G_{2}=$ incremento em área basal da idade $I_{1}$ a idade $I_{2} ; G_{2}=$ área basal futura $\left(G_{2}=G_{1}+d G_{2}\right) ; S_{1}=$ índice de sítio definido na idade atual (usando as curvas de índice de sítio polimórficas elaboradas para $P$. caribaea var. caribaea por Guera (2017), com cinco classes de sítio (SV = 10-13; SIV= 13-16; SIII= 16-19; SII= 19-22 e SI = 22-25); $L n=$ logaritmo neperiano; $R_{a j}^{2}=$ coeficiente de determinação ajustado; e $R M S E=$ raiz quadrada do erro médio quadrático.

As intensidades de desbaste testadas por classe de sítio estão resumidas na Tabela 1. A seleção de intensidades de $10 \%$ a $40 \%$ de retirada em área basal é devido aos valores baixos de incrementos médios anuais reportados na empresa Macurije por Aldana et al. (2006) $\left(6,5 \mathrm{~m}^{3} / \mathrm{ha}\right.$ /ano), Barrero et al. (2011) (10-12 $\left.\mathrm{m}^{3} / \mathrm{ha} / \mathrm{ano}\right)$ e Guera (2017) (11,05 $\left.\mathrm{m}^{3} / \mathrm{ha} / \mathrm{ano}\right)$. Intensidades maiores que os adotados (>40\%) podem resultar severas para os povoamentos. Intensidades de desbaste proporcionais às qualidades do sítio foram adotadas devido a que sítios de melhores capacidades produtivas podem soportar maiores intensidades de desbaste sem perda significativa da produção.

Três desbastes foram aplicados: o desbaste I cuja idade de aplicação foi determinada pelo critério de máximo incremento médio anual (IMA) em área basal (CAMPOS \& LEITE, 2017); o desbaste II aos 16 anos para melhorar a forma do fuste e da copa; e o desbaste III depois aos 26 anos para a aceleração do crescimento e redução do tempo de obtenção de árvores com maiores dimensões (SUÁREZ et al., 2002). Depois do desbaste III, os cortes finais foram simulados nas idades técnicas de rotação propostas por Barrero (2010) e Guera (2017).

Tabela 1. Intensidades de desbaste aplicadas por sítio.

\begin{tabular}{c|ccc}
\hline \multirow{2}{*}{ Sítios } & \multicolumn{3}{|c}{ Intensidades de desbaste aplicadas } \\
\cline { 2 - 4 } & I 1 & II 2 & III 3 \\
\hline I & $40 \%$ & $30 \%$ & $20 \%$ \\
II & $35 \%$ & $25 \%$ & $15 \%$ \\
III & $30 \%$ & $20 \%$ & $10 \%$ \\
IV & $20 \%$ & $15 \%$ & $10 \%$ \\
V & $20 \%$ & $15 \%$ & $10 \%$ \\
\hline
\end{tabular}


De acordo com Aldana et al. (2006), os povoamentos com densidades 0,3 - 0,4 não são desbastados. Os que apresentam densidades entre 0,8 e 1,0 e $D A P_{m} \geq 20 \mathrm{~cm}$ são desbastados a uma densidade não menor que 0,7 . Os povoamentos com densidades entre 0,8 e 1,0 e $D A P_{m}<$ $20 \mathrm{~cm}$ são desbastados a densidades remanescentes de 0,5 - 0,6 com aumento progressivo da probabilidade de obtenção de árvores com diâmetros maiores que $20 \mathrm{~cm}$, depois os sucessivos desbastes.

No presente, ao simular os três desbastes consecutivos em cada área, as áreas basais remanescentes são consideradas não severas, se o diâmetro médio das árvores é maior o igual a $20 \mathrm{~cm}$ com uma densidade final de 600 árvores/ha nos sítios I, II e III, o que equivale a uma área basal remanescente de $18,84 \mathrm{~m}^{2} / \mathrm{ha}\left(\approx 19 \mathrm{~m}^{2} / \mathrm{ha}\right)$. Com a mesma exigência em DAP médio e uma densidade final de 500 árvores/ha, a área basal remanescente considerada adequada para os sítios IV e $V$ foi $15,7 \mathrm{~m}^{2} / \mathrm{ha}\left(\approx 16 \mathrm{~m}^{2} / \mathrm{ha}\right)$. Depois das simulações, foram analizados o comportamento dos DAPs dos povoamentos remanescentes e das Intensidades de Desbaste (ID) nas diferentes classes de sítio (S) (relações DAP/S e ID/S).

O software SVS (Stand Visualization System) foi utilizado para a representação das vistas aéreas e em perspectiva dos povoamentos não desbastados e das diferentes intensidades de desbastes selecionadas. Nesse software, utilizando o método de desbaste pelo baixo com base no DAP (área basal), foram marcadas as árvores com DAP $\leq 20 \mathrm{~cm}$ de forma crescente (das árvores de menores DAP as de maiores DAP) até atingir o valor de área basal correspondente a intensidade de desbaste a ser aplicada.

\section{RESULTADOS E DISCUSSÃO}

\section{Determinação das idades de aplicação do primeiro desbaste nos plantios de Pinus caribaea var. caribaea}

Os resultados dos incrementos médios e correntes anuais em áreas basais por classe de sítio indicaram que a culminação da área basal acontece aproximadamente aos 4 anos nos sítios I, II e III e aos 5 anos nos sítios IV e V, sendo estas idades as escolhidas para a aplicação do primeiro desbaste nos sítios correspondentes (Figura 1 e Tabela 2). Isto indica que estas idades técnicas são inversamente proporcionais a capacidade produtiva do sítio conforme reportado por Leite et al. (2008).
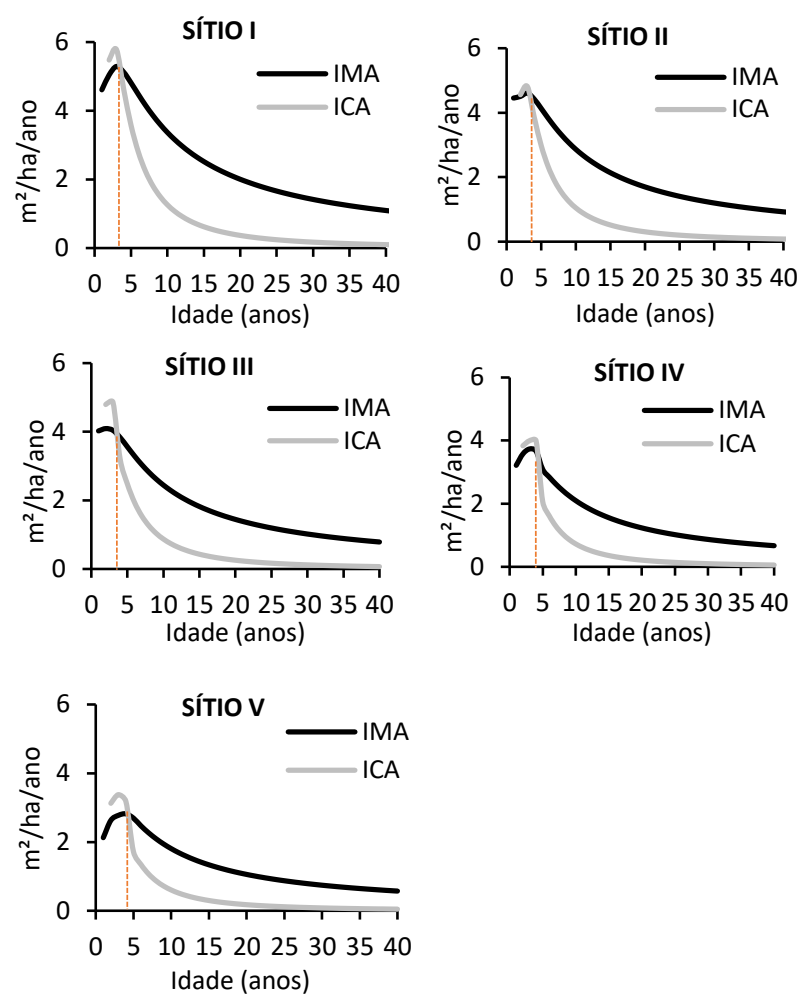

Figura 1. Incrementos médios e correntes anuais em áreas basais em plantios de $P$. caribaea var. caribaea.

\section{Simulações de desbastes em plantações de Pinus caribaea var. caribaea}

As simulações de desbaste se encontram nos gráficos da Figura 2. As simulações indicaram que a intensidade de $20 \%$ é a mais adequada para o sítio I, 15\% para o sítio II e $10 \%$ para os sítios III, IV e V, por serem as intensidades que geraram áreas basais remanescentes superiores ou iguais aos limites de adequabilidade estabelecidos (Tabela 2 e Figura 2). Segundo Simões et al. (1981), as intensidades de desbaste leves $(I \leq 10 \%)$ que resultaram adequadas para os últimos três sítios (SIII, SIV e SV) podem não causar efeito sobre o crescimento das variáveis dendrométricas, principalmente os diâmetros devido a que a quantidade de árvores retirada é muito baixa para causar o efeito desejado. Esses desbastes moderados favorecem mais o crescimento em altura em coníferas (ASSMANN, 1970).

Depois da aplicação dos desbastes, tanto as intensidades de desbaste como os DAPs médios estimados nos cortes finais realizados nas idades de rotação propostas por Barrero (2010) e Guera (2017) foram proporcionais a qualidade do sítio (Figura 3). 
Tabela 2. Idades de aplicacão dos desbastes e áreas basais remanescentes em diferentes qualidades de sítio.

\begin{tabular}{|c|c|c|c|}
\hline Índices de sítio & Desbastes & Idades de aplicação (anos) & Área basal remanescente $\left(\mathrm{m}^{2} . \mathrm{ha}^{-1}\right)$ \\
\hline \multirow{4}{*}{ SI } & Primeiro & 04 & 19,259 \\
\hline & Segundo & 16 & 24,545 \\
\hline & Terceiro & 26 & 21,362 \\
\hline & Corte Final & $31^{*}$ & 21,834 \\
\hline \multirow{4}{*}{ SII } & Primeiro & 04 & 17,556 \\
\hline & Segundo & 16 & 23,508 \\
\hline & Terceiro & 26 & 21,705 \\
\hline & Corte Final & $32 *$ & 22,253 \\
\hline \multirow{4}{*}{ SIII } & Primeiro & 04 & 16,026 \\
\hline & Segundo & 16 & 22,435 \\
\hline & Terceiro & 26 & 21,894 \\
\hline & Corte Final & $33^{*}$ & 22,508 \\
\hline \multirow{4}{*}{ SIV } & Primeiro & 05 & 13,894 \\
\hline & Segundo & 16 & 19,172 \\
\hline & Terceiro & 26 & 18,672 \\
\hline & Corte Final & $34^{*}$ & 19,240 \\
\hline \multirow{4}{*}{ S V } & Primeiro & 05 & 12,793 \\
\hline & Segundo & 16 & 18,336 \\
\hline & Terceiro & 26 & 18,806 \\
\hline & Corte Final & $35^{*}$ & 19,415 \\
\hline
\end{tabular}

*Idades de rotação reportadas por Barrero (2010) e Guera (2017)

Prognose de área basal (sem desbaste)
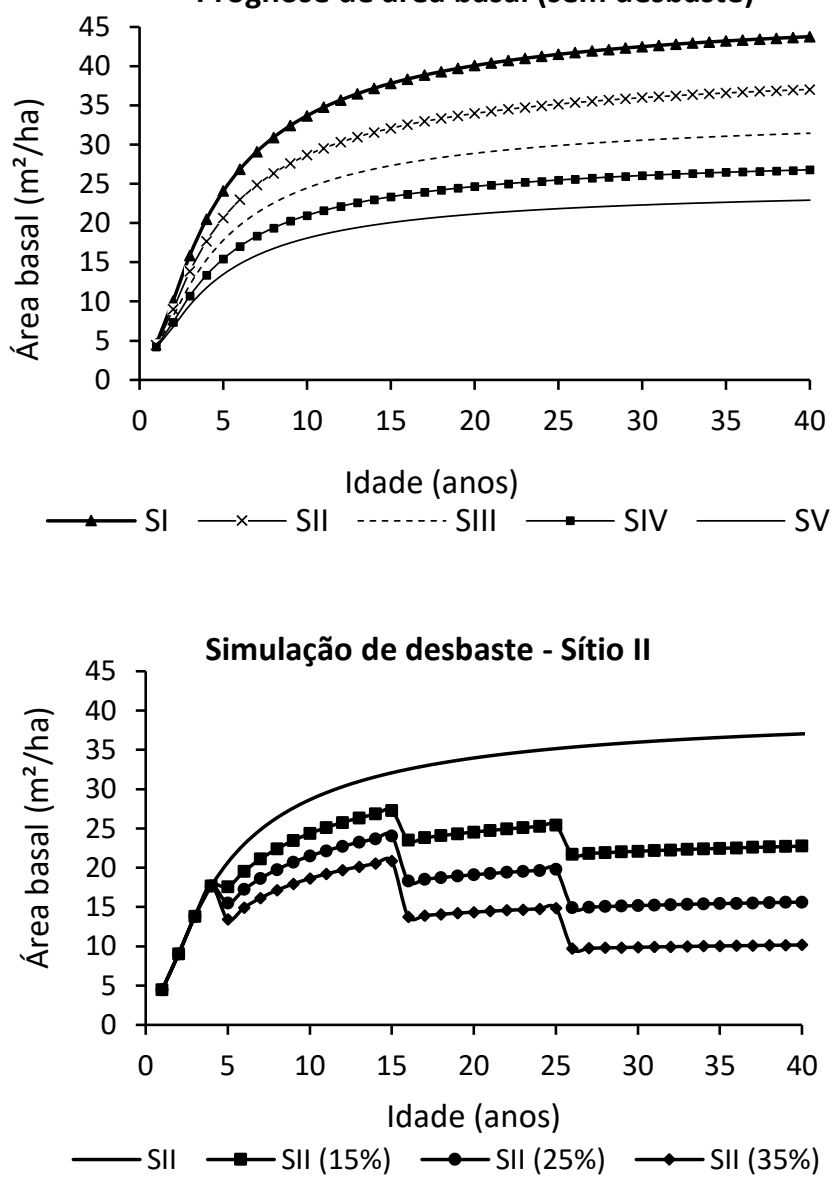
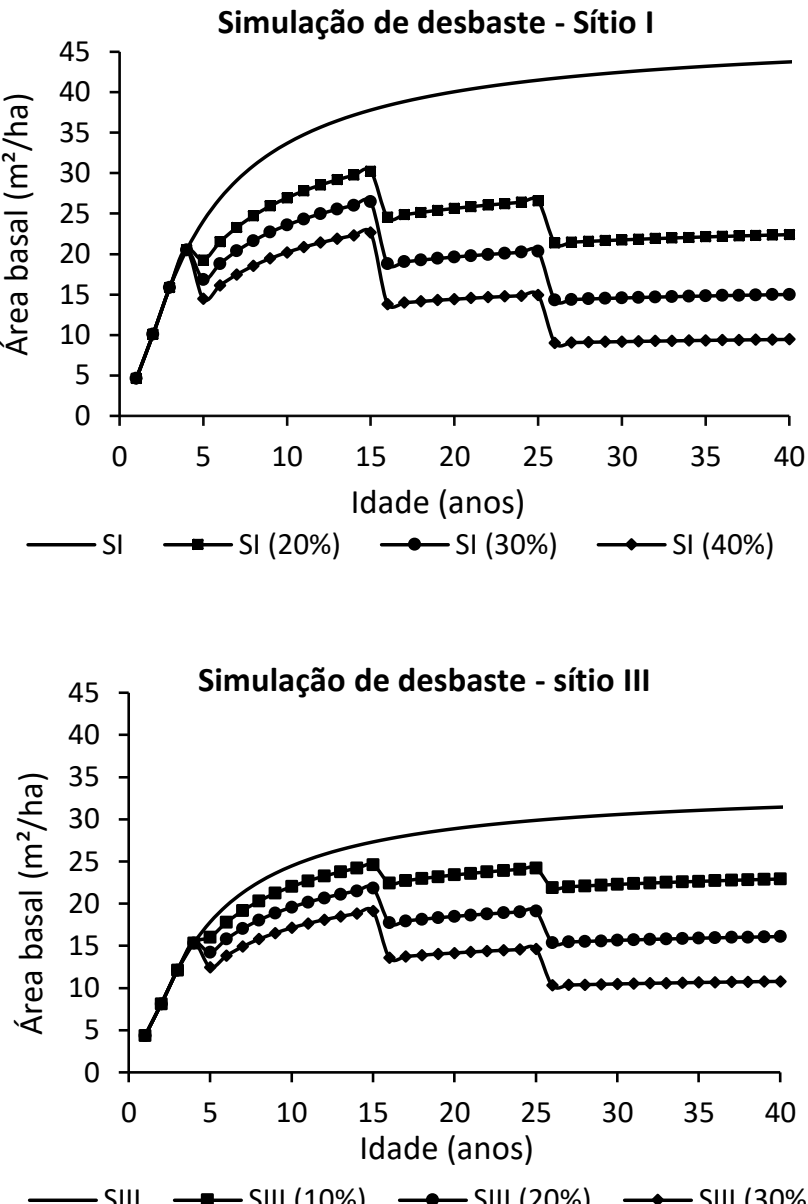

Figura 2. Simulações de desbastes por qualidade de sítio em plantios de $P$. caribaea var. caribaea na empresa Macurije, Cuba. 


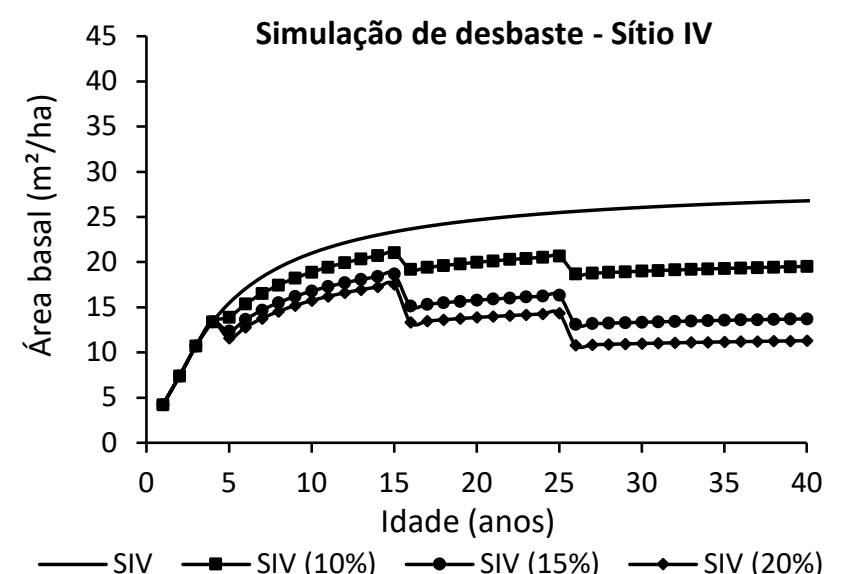

Figura 2. Continuação...

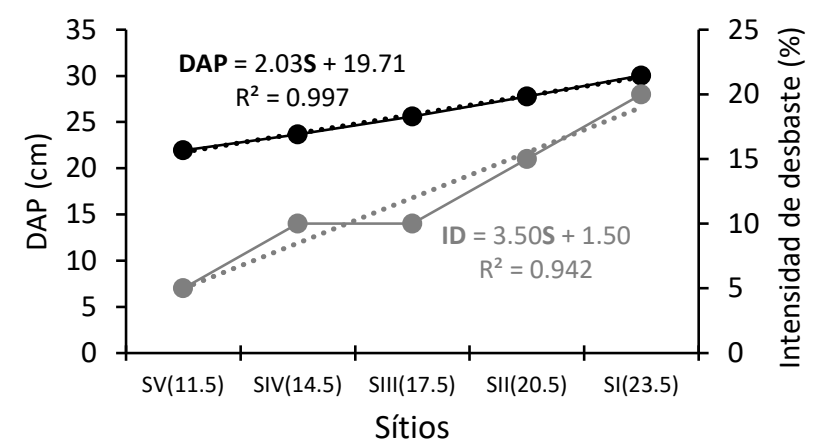

Figura 3. Relações $\mathrm{DAP} / \mathrm{S}$ e ID/S nas simulações de desbastes realizadas nos plantios de $P$. caribaea.

Representação das vistas aéreas e em perspectiva das estruturas dos povoamentos remanescentes

As representações das intensidades consideradas

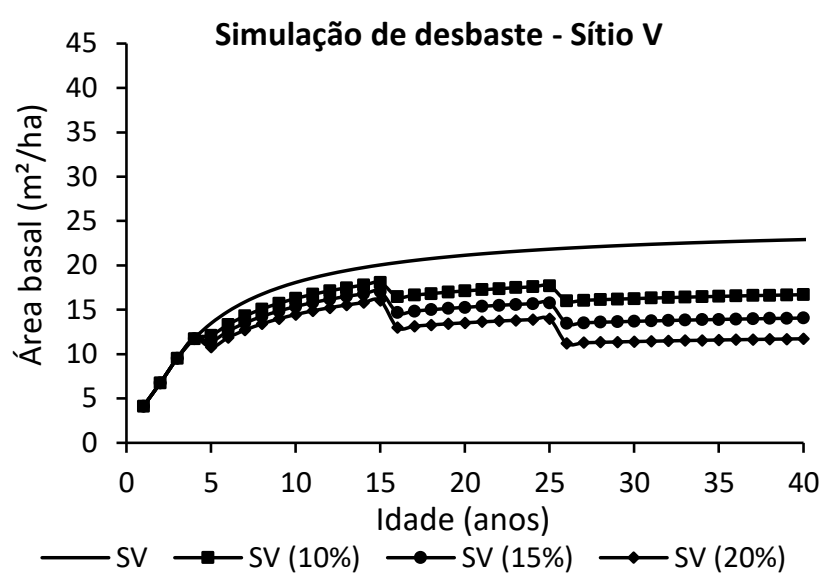

adequadas para cada um dos sítios (20\% para o sítio I, 15\% para o sítio II, $10 \%$ para os sítios III, IV e V) se encontram na figura 4. Se observam nas vistas em perspectiva que as intensidades escolhidas para cada classe de sítio não são severas e os povoamentos remanescentes presentam boa densidade e estrutura para a obtenção de árvores de maiores dimensões que atendam as exigências dendrométricas das serrarias, principalmente DAP $\geq 20 \mathrm{~cm}$.

As vistas aéreas (Figura 4) permitiram obter as coberturas de dossel de cada cenário. A porcentagem média de cobertura de dossel (92\%) dos povoamentos não desbastados foi reduzida a $76,4 \%, 73,6 \%$ e $70,8 \%$ com os desbastes de 10, 15 e 20\%, respectivamente. Essa abertura proporcionaria mais espaço de crescimento, principalmente em diâmetro, e mais transmitância de luz a favor das árvores remanescentes.
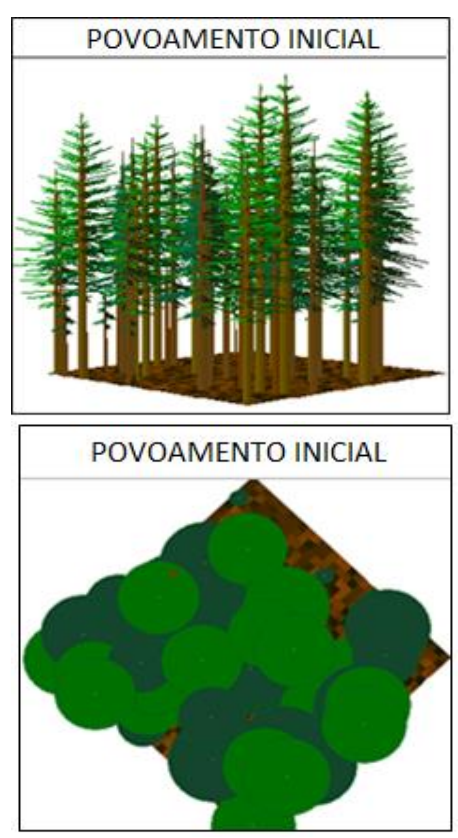
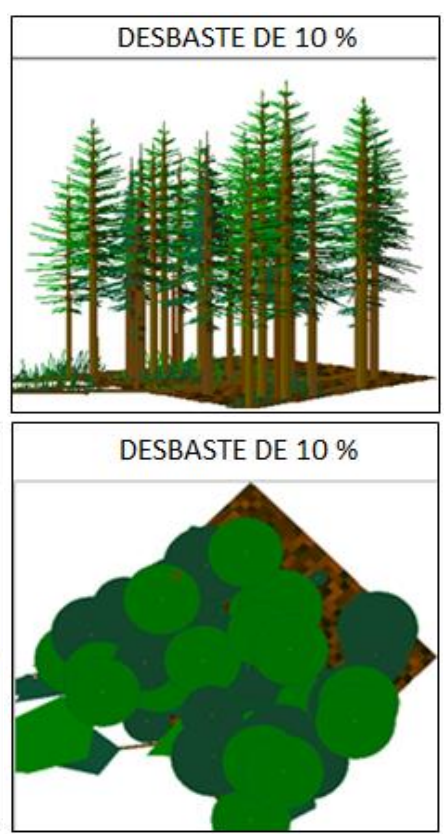

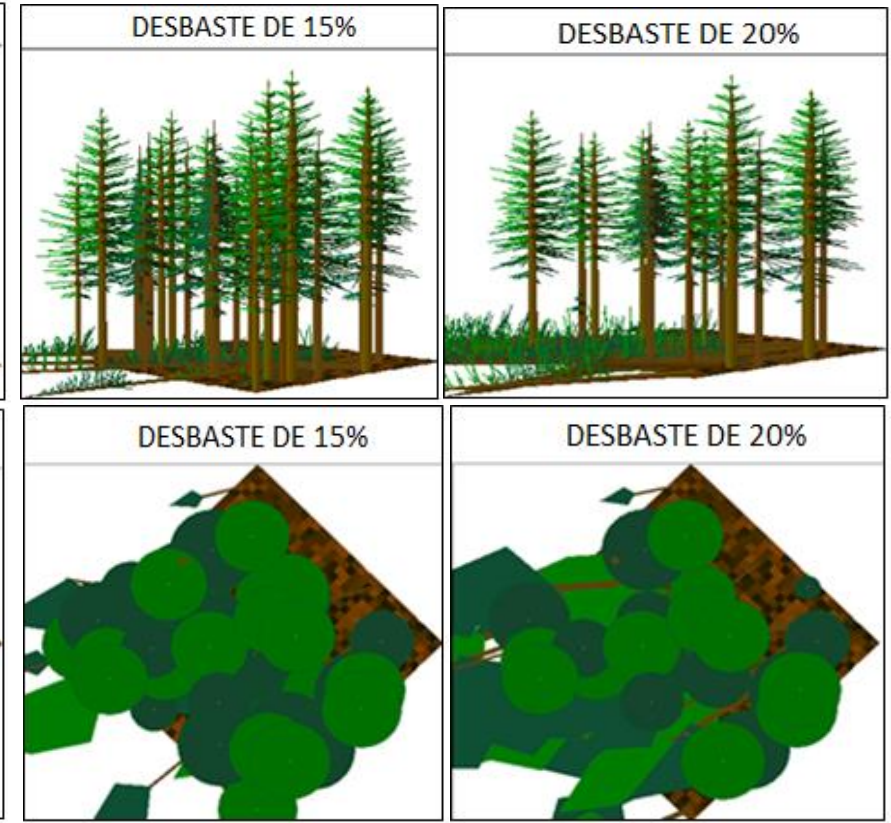

Figura 4. Vistas em perspectiva (acima) e aéreas (abaixo) dos povoamentos de Pinus caribaea var. caribaea para os desbastes selecionados na empresa florestal Macurije, Cuba. 


\section{CONCLUSÕES}

A consistência dos desbastes simulados indica que as equações do sistema de Buckman podem ser empregadas para a prognose da produção, com ou sem desbastes, em povoamentos de Pinus caribaea var. caribaea na empresa florestal Macurije;

As simulações indicam que a intensidade de $20 \%$ foi a mais adequada para o sítio I, 15\% para o sítio II e 10\% para os sítios III, IV e V na empresa florestal Macurije;

O sistema de visualização de áreas, SVS, permite obter uma aproximação visual da estrutura de povoamentos remanescentes depois da aplicação das intensidades de desbaste adequadas para cada sítio.

\section{REFERÊNCIAS}

ALDANA, E. et al. Proyecto de ordenación EFI Macurije. La Habana: Ministerio de la Agricultura; 2006.

ASSMAN, E. The principles of forest yield study. New York: Pergamon, 1970.

BARRERO, H. Modelo integral de crecimiento, perfil de fuste, grosor de corteza y densidad de la madera de Pinus caribaea Morelet var. caribaea Barret y Golfari: Estudio de caso EFI Macurije. 2010. 101p. (Tese de doutorado).

BARRERO, M.H. et al. Determinación del Turno de Corta para Pinus caribaea var. caribaea en la Empresa Forestal Integral "Macurije". Floresta e Ambiente, v.18, n.1, p.109-116, 2011.

BURKHART, H.E. et al. A comparation of growth and yield prediction models for loblolly pine. Virginia: School of Forestry and Wildlife Resources, 1981.

CAMPOS, J.C.C.; LEITE, H.G. Mensuração florestal: perguntas e respostas. 5.ed. Viçosa: UFV, 2017.

GUERA, O.G.M. Modelos matemáticos para auxílio à tomada de decisão no processo produtivo de Pinus caribaea Morelet var. caribaea Barr. \& Golf. na empresa florestal integral Macurije, Pinar Del Río, Cuba. 2017. (Tese de doutorado).

LEITE, H.G. et al. Uso da mensuração florestal em pesquisa e em manejo de povoamentos submetidos a desbaste. 3 Seminário Sobre Silvicultura em Florestas Plantadas, p.77-114, 2008.

MACHADO, C.C. Colheita florestal. Minas Gerais: Editora UFV, 2014.

MAGIN, E.K. Standortgerechte ertragsmittlung als teil der forsteinrichtung. Mitteilungen aus der staatsforst - erwaltung Bayerns, v.34, p.305-314, 1964.

PIENAAR, L.V. An approximation of basal area growth after thinning based on growth in unthinned plantations. Forest Science, v.25, n.2, p.225-232, 1979.

PIENAAR, L.V. et al. Predicting basal area growth in thinned slash pine plantations. Forest Science, v.31, n.3, p.731-741, 1985.
SANTOS, L.N. et al. Avaliação de custos da operação de extração da madeira com forwarder. Cerne, v.22, n.1, p.27-34, 2016.

SCOLFORO, J.R.S. et al. Simulação e avaliação econômica de regimes de desbastes e desrama para obter madeira de Pinus taeda livre de nós. Ciência Florestal, v.11, n.1, p.121-139, 2001.

SILVA, A.L. et al. Growth and yield prediction using the modified Buckman model. Revista Árvore, v.30, n.5, p.787-793, 2006.

SIMÕES, J.W. et al. Formação, manejo e exploração de florestas com espécies de rápido crescimento. Brasília: IBDF, 1981.

SUÁREZ, M.T. et al. Manual para la ejecución de la ordenación forestal. 2002. 